\title{
O USO DA MADEIRA NAS REDUÇÕES JESUÍTICO-GUARANI DO RIO GRANDE DO SUL. 6 - IMAGEM DE SÃO LOURENÇO MÁRTIR ${ }^{1}$
}

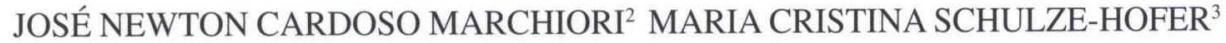

\section{RESUMO}

A madeira da imagem de São Lourenço Mártir, integrante do acervo do Museu das Missões, foi anatomicamente identificada como Cedrela fissilis Vellozo, espécie arbórea conhecida popularmente como "cedro", no sul do Brasil.

Palavras-chave: Anatomia da Madeira, Missões Jesuíticas, Rio Grande do Sul, escultura de São Lourenço.

\section{SUMMARY}

[Wood utilization in the Jesuitic-Guarani Missions from Rio Grande do Sul state, Brazil. 6 - Anatomical identification of Saint Lawrence Martyr's sculpture].

The wood of Saint Lawrence Martyr's sculpture, housed at the Missions Museum (São Miguel das Missões, Rio Grande do Sul state, Brazil), was anatomically identified as Cedrela fissilis Vellozo, a species named cedro (spanish cedar) in the region.

Key words: Wood Anatomy, Jesuitic Missions, Rio Grande do Sul state, Saint Lawrence's sculpture.

\section{INTRODUÇÃO}

De autoria desconhecida e grandes dimensões (222 x 97 x 77 cm), a imagem de São Lourenço Mártir integra o acervo do Museu das Missões (São Miguel das Missões, Rio Grande do Sul). Oca pela parte de trás, a escultura foi realizada com vários blocos de madeira encaixados e representa uma figura masculina jovem, de cabelos curtos e postura elegante, com nariz de feição européia, mas boca e rosto de traços indígenas. Como vestimenta, vê-se uma túnica larga, casula, sapato e manto com figuras fitomórficas (Figura 1A), de policromia infelizmente perdida. Restaurada em 1990/1991 por Ariston Correia Filho, a imagem recebeu produto preservativo.

O presente trabalho, que trata da identificação anatômica da imagem de São Lourenço Mártir, visa a contribuir para o conhecimento sobre o uso da madeira nas reduções JesuíticoGuarani do Rio Grande do Sul.

1 Recebido em 30-10-2008 e aceito para publicação em 27-11-2008.

2 Engenheiro Florestal, Dr., bolsista de Produtividade em Pesquisa do CNPq - Brasil, Professor Titular do Departamento de Ciências Florestais da UFSM, RS, Brasil. balduinia@mail.ufsm.br

3 Arquiteta, Dra., IPHAN - Instituto do Patrimônio Histórico e Artístico Nacional. schulze-hofer@gmx.de

\section{MATERIAL E MÉTODOS}

O material estudado consiste de uma amostra de madeira (Figura 1B,C), retirada da parte posterior e inferior da imagem. Os trabalhos de microtécnica e fotomicrografia foram realizados no Laboratório de Anatomia da Madeira do Instituto Nacional de Pesquisas da Madeira, em Lohbrügge, Hamburgo (Alemanha); os autores agradecem à Sra. Eda John, pela colaboração nestas tarefas.

Da amostra de madeira foram preparados corpos-de-prova, orientados para a obtenção de cortes anatômicos nos planos transversal, longitudinal radial e longitudinal tangencial. Os corpos-de-prova foram amolecidos por fervura em água, incluídos em polietilenoglicol 2000, e seccionados em micrótomo de deslizamento (modelo American Optical), regulado para a obtenção de cortes com espessura nominal de $20 \mu \mathrm{m}$. Os cortes anatômicos não sofreram coloração; no caso dos radiais, parte deles foi tratado com hipoclorito de sódio, com vistas a salientar a visualização de eventuais estruturas cristalinas nas células lenhosas. As fotomicrografias da Figura 2 foram tomadas com câmera Olympus AX, em diferentes aumentos. 

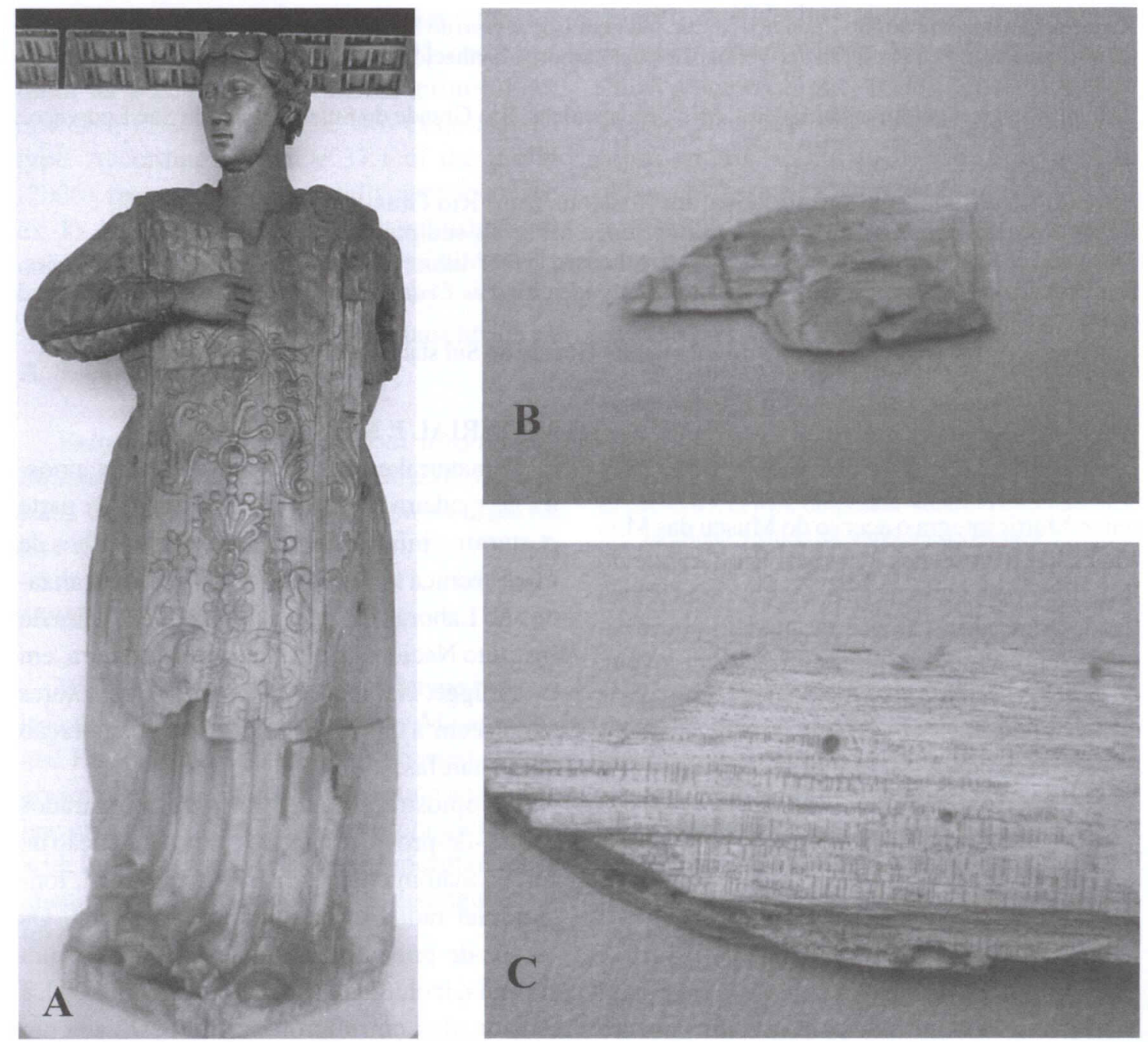

FIGURA 1 - Imagem de São Lourenço Mártir. A - Fotografia da imagem missioneira. B, C - Amostra (frente e verso) de madeira coletada. 


\section{DESCRIÇÃO DA MADEIRA}

Madeira porosa, de Magnoliophyta ou Angiospermae Dicotyledoneae (Figura 2A-E). Anéis de crescimento marcados por faixas de parênquima marginal (Figura 2A). Porosidade difusa (Figura 2A).

Vasos pouco numerosos $\left(6-9 / \mathrm{mm}^{2}\right)$, circulares ou ovais, de diâmetro pequeno a grande (60$300 \mu \mathrm{m})$, geralmente solitários, menos comumente geminados ou em múltiplos de 3-4 unidades, e com abundante óleo-resina (Figura 2A). Linhas vasculares retilíneas (Figura 2C). Placas de perfuração simples, horizontais ou ligeiramente oblíquas. Pontoações intervasculares alternas e poligonais, de 5-10 $\mu \mathrm{m}$ de diâmetro, com abertura elíptica inclusa, por vezes coalescente.

Parênquima apotraqueal marginal, em faixas regulares de 1-7 células de largura, mas também apotraqueal difuso e paratraqueal escasso (Figura 2A,B). Séries parenquimáticas axiais de 2-6 células, com abundante óleo-resina e, por vezes, com cristais romboédricos de oxalato de cálcio.

Raios pouco numerosos (4-7/mm), muito baixos até baixos, com menos de 25 células de altura e predominantemente bi-tri-tetrasseriados, com escassos uni e multisseriados (Figura $2 \mathrm{E}$, F). Estrutura radial homogênea até heterogênea, reunindo células procumbentes, no centro, e uma fileira marginal de células quadradas ou pelo menos mais altas, nas margens (Figura 2D).

Tecido fibroso proeminente, de fibras libriformes curtas a longas, estreitas a médias e de paredes muito delgadas a delgadas (Figura 2B, D, F).

\section{ANÁLISE DA ESTRUTURA ANATÔMICA}

A descrição anatômica acima exposta conduz, facilmente, à identificação do material como pertencente ao gênero Cedrela (Meliaceae), mediante chave dicotômica de Tortorelli (1956): lenho fundamentalmente vascular; madeira sem estrutura estratificada; vasos com perfurações simples; vasos lenhosos com pontoações alternas; ausência de canais intercelulares; poros em disposição não dendrítica ou ulmiforme; raios lenhosos bi a multisseriados, com escassos unisseriados; poros em número inferior a $45 / \mathrm{mm}^{2}$; parênquima principalmente apotraqueal; raios lenhosos com menos de $1 \mathrm{~mm}$ de altura; parênquima marginal sempre presente; poros pouco numerosos; e fibras com lúmen de $1 / 2$ a 3/4 do diâmetro total.

A checagem da estrutura observada com descrições anatômicas de Cedrela fissilis (Mainieri \& Chimelo, 1989; Tortorelli, 1956), bem como com lâminas da referida espécie, integrantes do acervo do Departamento de Ciências Florestais da Universidade Federal de Santa Maria, esclarece, finalmente, a identidade botânica do material: a imagem de São Lourenço Mártir foi realizada em madeira de cedro ou cedro-vermelho: Cedrela fissilis Vellozo.

A respeito do cedro, cabe salientar que não existe na flora regional espécie mais dócil para esculturas e obras de talha, aliada à boa durabilidade natural e acabamento. Comparado ao pinheiro-brasileiro (Araucaria angustifolia (Bert.) Kuntze), espécie utilizada na imagem missioneira de São José (Marchiori \& SchulzeHofer, 2009), a madeira de cedro é indiscutivelmente superior, sob quaisquer pontos de vista. De odor agradável, essa madeira também aceita muito bem a aplicação de pigmentos, pressuposto em esculturas com policromia.

\section{REFERÊNCIAS BIBLIOGRÁFICAS}

MAINIERI, C., CHIMELO, J. P. Fichas de características das madeiras brasileiras. São Paulo: IPT, 1979. $418 \mathrm{p}$.

MARCHIORI, J. N. C., SCHULZE-HOFER, M. C. $O$ uso da madeira nas reduções Jesuítico-Guarani do Rio Grande do Sul. 3 - Imagem de São José. Balduinia, Santa Maria, n. 15, p. 1-4, 2009.

TORTORELLI, L. A. Maderas y bosques argentinos. Buenos Aires: ACME, 1956. 910 p. 

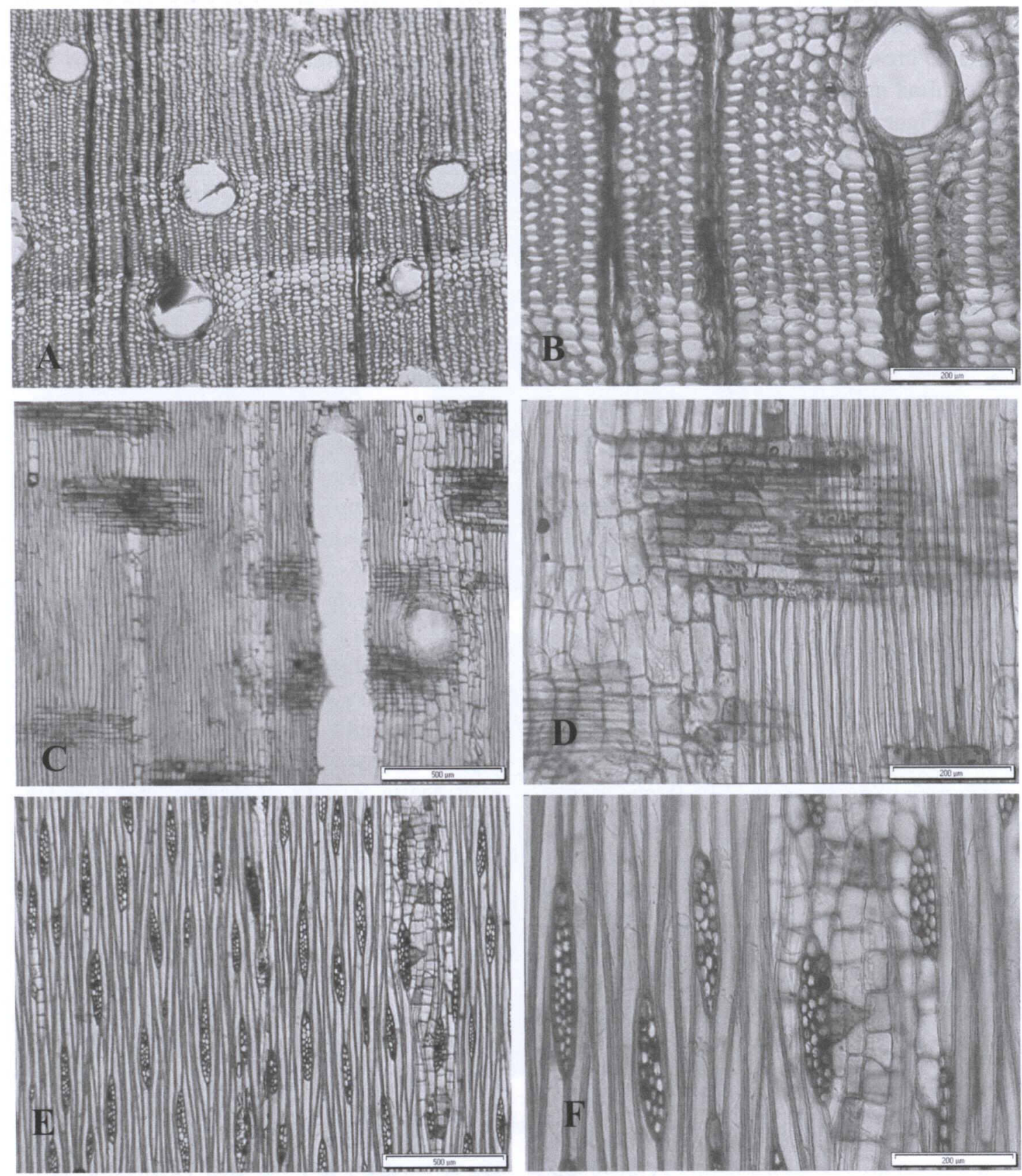

FIGURA 2 - Fotomicrografias da madeira da imagem de São Lourenço Mártir. A - Seção transversal, mostrando porosidade difusa, vasos pouco numerosos de diâmetro pequeno a grande, parênquima apotraqueal marginal em faixas e fibras de paredes finas. B - Mesmos aspectos do campo anterior, com maior aumento. C - Raios fracamente heterogêneos, linhas vasculares retilíneas e fibras de paredes finas, em seção radial. D - Mesmos aspectos do campo anterior, com maior aumento. E - Parênquima axial com várias células por série e raios pouco numerosos, predominantemente 2-4-seriados, com menos de 25 células de altura, em seção tangencial. F - Mesmos aspectos do campo anterior, com maior aumento. 